\title{
What is the potential of oligodendrocyte progenitor cells to successfully treat human spinal cord injury?
}

\author{
Robert A Watson ${ }^{1 *}$ and Trevor M Yeung ${ }^{2}$
}

\begin{abstract}
Background: Spinal cord injury is a serious and debilitating condition, affecting millions of people worldwide. Long seen as a permanent injury, recent advances in stem cell research have brought closer the possibility of repairing the spinal cord. One such approach involves injecting oligodendrocyte progenitor cells, derived from human embryonic stem cells, into the injured spinal cord in the hope that they will initiate repair. A phase I clinical trial of this therapy was started in mid 2010 and is currently underway.

Discussion: The theory underlying this approach is that these myelinating progenitors will phenotypically replace myelin lost during injury whilst helping to promote a repair environment in the lesion. However, the importance of demyelination in the pathogenesis of human spinal cord injury is a contentious issue and a body of literature suggests that it is only a minor factor in the overall injury process.

Summary: This review examines the validity of the theory underpinning the on-going clinical trial as well as analysing published data from animal models and finally discussing issues surrounding safety and purity in order to assess the potential of this approach to successfully treat acute human spinal cord injury.
\end{abstract}

\section{Background}

Clinicians currently have very limited treatment options when managing a patient with spinal cord injury (SCI). Symptom control, supportive care and rehabilitation are the mainstays of treatment [1] and a reversal of the injury process has, until recently, been science fiction. However, developments in the field of stem cells have led many to believe that regeneration of an injured spinal cord is indeed possible and one such approach is currently undergoing a phase I clinical trial [2]. In the first trial of its kind, oligodendrocyte progenitor cells (OPCs) derived from human embryonic stem cells (hESCs) will be injected into the spinal cords of patients with an acute thoracic SCI to assess safety and efficacy in restoring neurological function [3]. Initially hailed as a major advancement [4] and treated with optimism in the popular press [5], this trial has already experienced setbacks and was placed on clinical hold by the FDA in 2009 due to safety issues [6]. Whilst the trial has now been given

\footnotetext{
* Correspondence: robert.watson@gtc.ox.ac.uk

${ }^{1}$ Green Templeton College, Woodstock Road, Oxford, OX2 6HG, UK

Full list of author information is available at the end of the article
}

permission to proceed [7], lessons learnt from French gene therapy trials in 2003, in which retroviral gene insertion triggered leukaemia in some patients, show that any failures can potentially set back an entire field [8]. If similar serious issues of safety or efficacy arise, the effect on investors, regulators and patients may be extremely damaging.

\section{Pathogenesis of SCI Epidemiology}

SCI, caused by accidental injury in most cases [9], has universal importance but is particularly relevant to young people, with the average injury age 33 years [9]. A moment of trauma sets in motion a disease process ultimately resulting in partial or full paralysis and loss of some or all sensory input below the injury level, clinically known as incomplete or complete injury respectively [10]. With no cure currently available, patients can expect to spend the rest of their life in a wheelchair and approximately $16 \%$ of patients (those with complete tetraplegia [11]) face the prospect of life-long full paralysis from the neck down. In addition, many of the millions of

\section{C)


patients worldwide also experience incontinence [12], chronic pain [13] and psychiatric disorders $[14,15]$. This has an important social toll as many patients who have suffered an SCI experience significant disruption to their social and work lives, having a profound impact on their family and society around them [16]. Further, the direct costs of caring for patients with an SCI are enormous and are estimated to be in the region of $\$ 7$ billion per annum in the US [17].

\section{Primary and secondary disease}

The pathophysiology of SCI is biphasic, comprising a primary and secondary injury phase [18]. The primary injury phase refers to the injury itself, consisting of mechanical disruption of tissue caused by the force imparted by the primary injury mechanism. Although every human injury is unique, the most common injury mechanism is contusion (analogous to soft tissue bruising), often with prolonged compression due to crushing of the vertebrae [19]. Hyper-bending, hyper-stretching, rotation and laceration can also occur [10], although complete transections of the cord are rare and usually intact white matter is seen to traverse the lesion [20,21]. Whilst tissue damage can occur during this immediate phase, there is a surprising paucity of permanent pathological changes, underscoring the importance of secondary injury mechanisms [22].

The secondary injury phase depends on the time post injury and the processes occurring (summarised in Figure 1). Most damage and cellular loss occurs during the acute and intermediate phases where an extensive range of processes result in widespread apoptosis and necrosis of both neurons and oligodendrocytes, leading to neurological deficits [22-24]. The late intermediate and chronic phases are characterised by progressive degeneration, accompanied by attempts at endogenous repair [19]. Morphological changes associated with the chronic phase (Figure 1) are significant barriers to any cell replacement therapy and hence the clinical protocol for the use of OPCs involves administration during the intermediate phase, 7-14 days post injury $[25,26]$.

\section{Stem cell therapies and $\mathrm{SCl}$}

It is possible to classify 'stem cells' into two broad categories, embryonic and somatic; the latter term including all stem cells present in the adult as well as those found in foetal and neonatal tissues [27]. Embryonic stem cells are derived from the human blastocyst and maintain the ability to differentiate into any cell type (pluripotency) [28], whilst somatic stem cells are able to differentiate into a limited number of cell lineages (multipotency). It is this ability to differentiate into a variety of cell types, as well as secrete growth factors, that has gained interest from the field of spinal cord injury. It is hoped that stem cells can be used to replace neural cells lost during the injury process and stimulate a repair environment [29]. A number of stem cell types including mesenchymal stem cells, olfactory ensheathing cells and neural stem cells have been considered for use in SCI. However, further discussion of the use of these cell types is outside the scope of this article and is well reviewed elsewhere [27,29-33].

The cell type currently being trialled in human patients, and the focus of this article, is the oligodendrocyte progenitor cell. These cells are derived from human embryonic stem cells by culturing them in conditions to drive commitment to an oligodendroglial lineage $[34,35]$. Once purified, up to $95 \%$ of these cells display markers characteristic of oligodendroglial cells - GalC, RIP and O4 - and morphologically resemble oligodendroglial cells [26]. These progenitors can then be injected into the spinal cord where, in a demyelinating environment, they further differentiate into oligodendrocytes - the myelinating cells of the central nervous system [26]. In the human SCI lesion site, it is hoped that OPCs will work as a "combination therapy" [29] - phenotypically replacing lost oligodendrocytes and hence remyelinating axons that have become demyelinated during SCI, as well as secreting neurotrophic factors to establish a repair environment in the lesion [29].

This review sets out to assess the potential of this treatment to successfully heal SCI by first looking at the role of demyelination in the pathogenesis of SCI. We then assess the importance of trophic support and the repair environment before analysing in vivo models of OPC treatment. Finally, practical, safety and ethical issues will be discussed.

\section{Discussion}

\section{The role of demyelination and axonal sparing in SCI}

One of the key premises of using OPC transplants for treatment of SCI is that demyelination is a major contributor to the pathogenesis of the injury. Clearly, in order for remyelinating therapies to succeed there must be appropriate targets - i.e. naked, intact axons - in which function is restored to some degree following treatment. Somewhat surprisingly, the existence of such targets following human $\mathrm{SCI}$ is controversial and casts doubt on much of the fundamental science underlying OPC treatment. Whilst a number of animal studies $[36,37]$ have demonstrated myelin loss with sparing of the associated axon - so-called 'primary demyelination' - the extent to which this occurs following human injury is ambiguous and a number of post mortem studies of human SCI have suggested that it may not occur to a significant degree $[20,22,38]$.

It may be possible to explain the observed difference in the extent of primary demyelination between post mortem human samples and animal models. Experimental data demonstrates that axons need myelin for trophic 


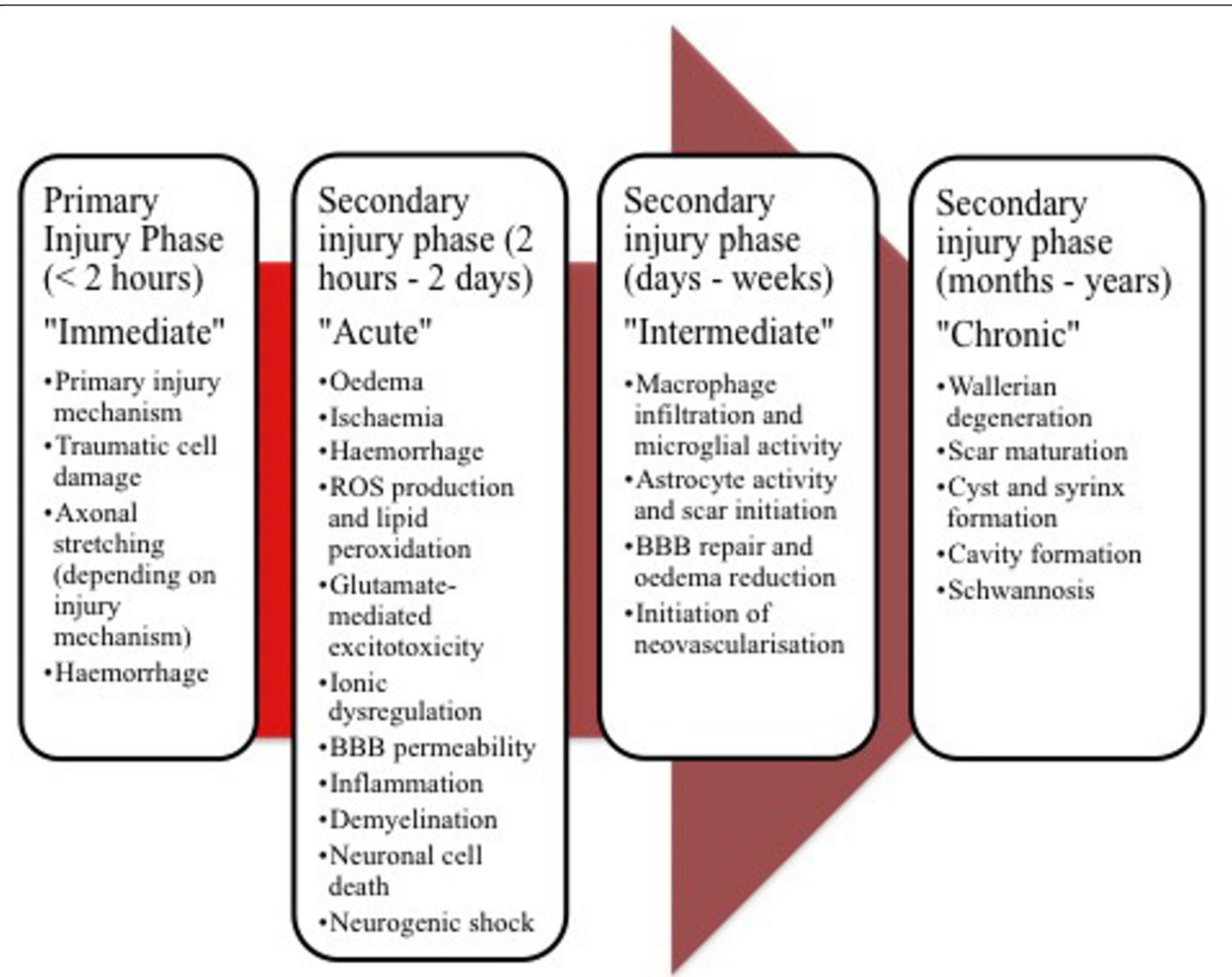

Figure 1 The key events following SCI. Adapted from [19-22]. BBB: Blood Brain Barrier; ROS: Reactive Oxygen Species.

support - mice missing two major myelin proteolipids, PLP and DM-20, typically show axonal swelling and degeneration [39]. Therefore any naked axons in humans may degenerate if they are not provided with support from oligodendrocytes and hence wouldn't be detected post mortem. Additional mouse data has supported this theory by showing a close correlation between myelin status and axonal survival [40].

Nonetheless, there are a number of inconsistencies with this explanation. Firstly, investigations in rats have identified chronically demyelinated axons [37], suggesting that some axons are capable of surviving without oligodendrocyte support. Additionally, were this explanation valid, then one would expect to see naked axons in acute or intermediate stage post mortem lesions, before they had time to degenerate. However, this is not reported to be the case $[20,22,38]$.

In summary, the role of demyelination is far from clear. Whilst some animal studies [36,37] suggest that naked, primary demyelinated axons - the target for OPC treatment - exist, post mortem human studies do not corroborate this $[20,22,38]$. This disparity could be due to the explanation given above, however, as discussed, this has a number of caveats. Nonetheless there could be other reasons for the conflicting results between human and animal studies such as the fact that post mortem samples - particularly from acute or intermediate phase lesions - necessarily come from injuries associated with high mortality and hence represent a more severe lesion. As suggested by Guest et al (2005), primary demyelination is more likely in less severe injury where axons can survive but oligodendrocytes cannot [38]. Perhaps, as suggested by Rowland et al, emerging magnetic resonance imaging technologies such as magnetization transfer and diffusion tensor imaging which allow the structural integrity of tissue to be imaged in live patients will clarify the situation in humans [19].

Overall, despite the prominent role for demyelination suggested in animal studies, a lack of consensus on the 
importance of this process in humans creates uncertainty regarding how successfully OPCs can treat human SCI. Indeed, even if remyelination is a successful strategy, there are many barriers to clinical improvement. For example, glial scar formation can create a physical barrier to OPCs whilst a number of molecules can have an inhibitory effect on OPCs. For example, both chondroitin sulphate proteoglycans (CSPGs) and TNF- $\alpha$ found within the scar have been shown to reduce OPC growth $[41,42]$, whilst other studies have shown that bone morphogenic protein (BMP) produced by astrocytes can reduce OPC differentiation into oligodendrocytes and promote differentiation into astroctyes [43].

\section{Trophic support and the importance of a repair environment}

OPC transplantation is a dual strategy, aiming not just to allow remyelination but also providing trophic support and a repair environment [44]. Spinal cord injury sets in motion a plethora of repair mechanisms, including endogenous remyelination and increased expression of a number of neurotrophic factors such as transforming growth factor- $\beta 2$ (TGF- $\beta 2$ ) and brain-derived neurotrophic factor (BDNF) $[45,46]$. Such up-regulation is thought to contribute to neuroprotection and even axonal sprouting [47]. However, axonal sprouting and endogenous repair is often abortive - due, in part, to an insufficient repair environment to overcome inhibitory mechanisms or promote maintained regeneration [48]. Moreover, although endogenous remyelination is often seen following SCI, it is usually functionally and anatomically incomplete [48-50]. It is therefore hoped that the grafting of a large number of OPCs soon after injury will create a 'repair environment' and allow these processes to develop further.

A host of evidence is weighing up in favour of this theory - OPCs are capable of producing numerous neurotrophins including midkine, TGF- $\beta 2$ and BDNF, contributing to a repair environment [51] and even promoting neurite outgrowth of rat sensory neurons in vitro [51]. In vivo studies (discussed in more detail below) have also suggested that OPC transplantation can significantly alter lesion pathogenesis and influence gene expression towards an uninjured pattern [52]. Indeed, in one experimental system, exposure of media conditioned by OPCs and oligodendrocytes alone was enough to increase the survival and axonal lengthening of neurons [53]. Therefore it is possible that even in the absence of remyelination, OPC transplantation may bring clinical improvement by providing trophic support and creating a regenerative environment, preventing the cellular damage and apoptosis seen in the secondary injury phase.

Despite this, eliciting neural regrowth is an ambitious goal as despite early optimism, neurotrophin based therapies, which aim to induce a repair environment, have been largely unsuccessful [54-56] and harnessing this process has remained elusive. Moreover, sprouting can also be pathogenic as new connections made by sensory afferents can lead to neuropathic pain [57] and autonomic dysreflexia [58]. Further, the inflammatory milieu following SCI is extremely complex and so the timing of any acute graft needs to be extremely carefully considered [59]. Hence whilst attempting to provide a supportive environment is a reasonable approach, it may be difficult to achieve in practice.

In summary, the potential benefit of remyelination remains controversial due to disagreements in the role of this process in human SCI. In addition, even if a remyelinating strategy is the correct one, there are a number barriers to success remaining including scar formation, inhibitory molecules and the complexity of the inflamed lesion. The latter also makes generation of a repair environment somewhat complex. These factors leave challenges to be overcome in the development of this therapy.

\section{In vivo evidence for potential of OPC transplantation}

Despite much debate surrounding the underlying principles of the potential of OPC transplants, a number of whole body in vivo experiments have been conducted to assess OPC-based therapy. The most important of these in the public domain, cited on the announcement of the clinical trial [4], is that of Keirstead et al (2005) [44]. The authors successfully demonstrated that injection of OPCs into rats with a thoracic contusion SCI seven days postinjury led to remyelination and restoration of some locomotor function. A similar study into cervical SCI [52], conducted by the same group, obtained similar results demonstrating that OPC transplantation can improve forelimb motor function as well as altering lesion pathogenesis; shown by increased white and grey matter sparing, decreased cavitation and altered gene expression [52]. This, too, was claimed to be "proof-of-concept" for the OPC clinical trials in a separate press release [60]. Subsequently, other groups have also shown neurological improvements following OPC injection into rodent models of SCI, further validating this approach [61-63]. Whilst these papers $[44,52]$ undoubtedly offer strong evidence for the promise of OPC therapy, there are a number of considerations to be made before these results can be applied to human therapy.

Firstly, contusion injury was produced by an 'impactor' a device which transiently delivers a specific force to the posterior of the spinal cord [64]. It is questionable how accurately this models human SCI where a variety of injury mechanisms often occur anteriorly [65], followed by prolonged compression, spinal fractures [66], haemorrhage and inflammation [67] and serious systemic injuries. 
Secondly, all SCIs were elicited under anaesthesia, followed by sterile wound closure and antibiotics $[44,52]$. Anaesthesia is known to have neuroprotective properties $[68,69]$, and may therefore alter the injury outcome, whilst antibiotics prevent infection, a factor that can exacerbate human SCI [9]. Thirdly, all animals were surgically prepared before injury - the paravertebral muscles were dissected and the spinal laminae removed. This procedure is known to reduce secondary disease processes such as swelling and oedema, altering disease pathogenesis [70]. Furthermore, these studies used locomotor function as a guide for neurological improvement but made no attempt to examine sensory or autonomic function - something that any treatment of SCI needs to address. Additionally, in the 2005 study, locomotion was assessed, in part, using the Basso Beattie and Bresnahan (BBB) scale [44], the sensitivity and reproducibility of which has been criticised [71]. Finally it is of interest to note that the authors of the 2005 study declare "no potential conflict of interest" [52] despite their work being funded by the company running the clinical trial, and being named by the latter as 'collaborators' [60]. This is probably of no consequence, but increased transparency would likely bestow greater confidence in the results obtained.

Whilst it is possible to criticise the extrapolation of animal data to humans, particularly in the context of SCI [72], one must bear in mind that whilst small-animal models may be flawed, they are still an important tool and live in vivo experiments are a crucial element of preclinical investigation. In spite of the aforementioned conflict of interest, the studies were rigorously conducted with appropriate controls and blinding of investigators where necessary. The fact that significant positive results were obtained, for both thoracic and cervical injury, provides a reasonable basis for development of this treatment. Whilst historically, promising animal data has often translated poorly into clinical success [72], it remains to be seen whether this will be true in this case.

\section{Practical issues}

\section{Safety and purity}

Transplanting pluripotent cells derived from embryos into adult humans clearly has associated risks. Two major possible adverse effects are teratoma formation and allogeneic rejection but a number of other complications could also potentially arise. Issues surrounding the safety and purity of the OPCs need to be carefully considered, as they could be a major barrier to the success of this therapy.

\section{Teratoma formation}

Human embryonic stem cells (hESCs) share a number of phenotypes with tumour cells - for example a rapid replication rate, genetic instability and telomerase activity [73]. On injection into immunodeficient mice, hESCs inevitably form teratomas (benign tumours comprising of tissue from all three embryonic layers) and indeed this association is so strong that this has become a test of pluripotency [73]. To mitigate the risk of teratoma formation, it is possible to employ one of three strategies: differentiation of pluripotent stem cells, manipulation of genetics to prevent tumorigenesis or careful surveillance and removal of any tumours that form in the patient [74].

Therapies involving OPCs are applying the first of these strategies by pre-differentiating hESCs into progenitor cells, abrogating the risk of teratoma formation [26]. Throughout intensive preclinical screening no evidence of aberrant growth or teratomas was found [75], implying that this strategy was successful. However, the risk of tumour formation a number of years after grafting, or due to contamination with undifferentiated hESCs, cannot be eliminated, especially as it is extremely difficult to obtain OPCs with $100 \%$ purity $[34,44]$. New culture techniques may improve purity (discussed below) but the risk of contamination remains valid. Indeed, during animal studies, non-neural tissue and cysts were found in some cases (Figure 2) and the current trial was placed on clinical hold for over a year pending further investigation by the FDA [6]. Whilst the trial has now resumed, it is not possible to predict the long-term consequences and risks at this stage.

\section{Immunogenicity and xenogenic culture}

Studies evaluating the immunogenicity of OPCs indicate that they elicit only a mild immune response [76], perhaps a product of the low immunogenicity of hESCs $[77,78]$, although some authors have suggested that this may not always be the case [79]. Either way, OPCs are an allogeneic transplant and as such pose a risk of immune rejection and subsequent exacerbation of any lesion. For this reason, the trial protocol includes low-dose immunosuppression

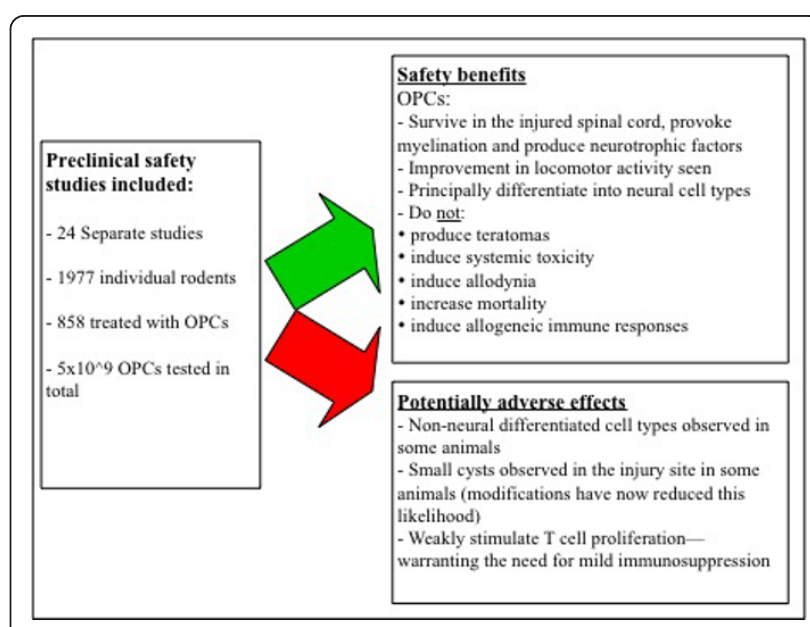

Figure 2 Conclusions from non-clinical safety studies of the OPCs to be injected into human spinal cords. Adapted from [25]. 
$[2,25]$. However, immunosuppressive therapy is known to have a number of side effects and in fact the first patient in the current phase I trial experienced a "mild" adverse event relating to tacrolimus (Figure 3 ).

The propensity to cause immune rejection or tumour formation is increased if the sample of cells grafted is impure. Many differentiation protocols, including the one used for the on-going trial [80], still use xenogenic products which can lead to alterations in cell surface molecules and carries a risk of pathogen cross-transfer. Recent advances have led to the emergence of xeno-free culturing protocols [81] which may facilitate the derivation of purer samples of donor cells and hence may help to mitigate the chance of adverse events.

Overall, risk analysis and preclinical testing for OPCs has been thorough and many other potential side effects such as allodynia or adverse effects on locomotion have been extensively screened for (Figure 2 ) and found to be of minimal risk $[25,82]$. However, it is not possible to ever eliminate the risk of adverse events and due to the variety and capriciousness of side effects, combined with cautious regulation, safety concerns could prove a serious hindrance to OPC treatment.

\section{Commercial viability}

OPCs are commercially viable due to the fact that they are durable, capable of tolerating freeze-thaw cycles and immortal [29]. This makes laboratory handling straightforward and standardisation and scaling up of manufacturing possible. Commercial viability is a very important factor for bringing new treatments to the clinic and the fact that OPCs fulfil these criteria enhances their potential to succeed. However, were OPCs to suffer a major setback during their first trial, investments - currently sustaining the on-going trial - may start to wane, thus jeopardising any future potential success.

\section{Ethical issues}

Due to complex ethical issues [83], there is a corpus of opposition to hESC research and associated therapies [84]. These ethical dilemmas are diverse, but in summary,

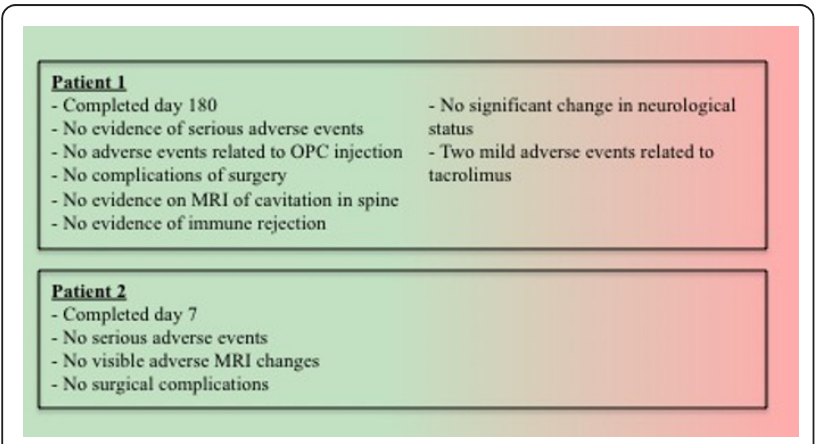

Figure 3 Outcomes reported in June 2011 of the phase I clinical trial of OPCs in human lesions. Adapted from [91] opposition tends to focus on the fact that research using human embryos violates the sanctity of life, with necessary destruction of these embryos tantamount to killing a human and hence morally unjustifiable [85]. Proponents of hESC research would counter that the moral status of a blastocyst is ambiguous and that whilst destruction of an embryo is undesirable, it is vindicated by the benefits it brings [85]. Furthermore, many embryos are 'spares' from IVF clinics, destined for destruction [85]. This is a simplistic overview, but regardless of any debate, opposition to this work is likely to always remain. Although private corporations will probably always be able to continue with hESC research, especially in an international context, any failures in this field would do little to quell opposition, potentially slowing future progress.

Recently, ethical concerns have also been raised regarding the on-going clinical trial. In particular, Bretzner et al (2011) raised objections to the design and patient population [86]. They claim that patients diagnosed with an acute SCI may be especially vulnerable to "therapeutic misconception", whereby they believe and are motivated by the idea that they will gain therapeutic benefit from the trial [86]. Further, they suggest that enrolling patients in the acute phase risks jeopardizing any spontaneous recovery and that there are more appropriate patient populations for a phase I safety trial of OPCs [86]. Whilst those responsible for the trial have strongly defended the chosen protocol [87] and other commentators have recently written critiques of Bretzner et al's article [88], it is clear that this pioneering study is, and will continue to be, subject to intense scrutiny and opposition. This pressure is likely to augment the consequences of any success or failure.

\section{Progress of the clinical trial}

The on-going phase I clinical trial into the use of OPCs for spinal cord injury has now been in progress for 9 months. Two patients have so-far undergone treatment and updates on the trial have recently been given at conferences in the first half of 2011 [89]. The trial is continuing to recruit patients [89]. The investigators state that "no serious safety issues have occurred to date" [90] and whilst no conclusions can be drawn until the trial has reached completion and the data appropriately collected and analysed, it is promising that there have been no major setbacks since its commencement (Figure 3) [91]. It should also be noted, however, that as this is a phase I clinical trial, the primary outcome is safety. Hence it will not be until the completion of phase II and III efficacy trials that inferences about the effectiveness of this therapy can be confidently drawn.

\section{Summary}

This review set out to assess the potential of OPCs to treat $\mathrm{SCI}$ by examining injury pathogenesis, current data 
from whole-body in vivo models and practical considerations. The situation surrounding pathogenesis is unclear, with opinion regarding the role of demyelination in human injury divided. Animal data - albeit from researchers keen to develop new technologies - suggests an important role for demyelination whilst clinical samples, notwithstanding their own caveats, indicate the contrary. Resolution of this issue may only come with new technologies or indeed the outcome of the planned trial and it is possible that OPCs will have clinically beneficial effects on the course of SCI independent of remyelination by providing trophic support in the injured spine.

Whole-body models have been promising, although extrapolation of rodent data to complicated human injury is questionable and history warns caution in this regard. There are numerous safety and purity issues regarding the culture mechanisms and potential tumorigenic nature of OPCs and any problems may lead to major setbacks for the field. Finally whilst the investment and ethical climate is currently favourable, turbulence in either of these facets could hinder future treatments.

In summary, OPCs have the potential to treat $\mathrm{SCI}$, but, as discussed in this review, there are many hurdles to overcome and numerous uncertainties. So far, animal studies have shown that any observable improvements are modest and that OPC transplants are only successful in acute lesions [44], so chronically injured patients or those expecting miracles risk disappointment. Nonetheless, SCI is a field in need of progress, exemplified by the fact that many patients are so desperate for a cure that they are driven abroad for risky and expensive procedures [92-94]. Only time will tell if OPCs will treat SCI, but whilst they have potential, there is at least hope for success.

\section{Author details \\ ${ }^{1}$ Green Templeton College, Woodstock Road, Oxford, OX2 6HG, UK. ${ }^{2}$ Stanford University School of Medicine, CCSR 3100, 269 Campus Drive, Stanford, CA 94305, USA.}

\section{Authors' contributions}

RAW elaborated the general structure of the manuscript and drafted it. TMY critically revised the draft. All authors have read and approved the final version of the manuscript.

\section{Competing interests}

The authors declare that they have no competing interests.

Received: 20 April 2011 Accepted: 23 September 2011 Published: 23 September 2011

\section{References}

1. Spinal Injury Network. [http://www.spinal-injury.net/treatment-of-spinalcord-injury.htm], Accessed 29th July 2011.

2. ClinicalTrials.gov. [http://www.clinicaltrials.gov], Search for: Trial ID: NCT01217008. Accessed 29th July 2011.

3. Geron Corporation: Information for patients, clinical trial details. [http:// www.geron.com/patients/clinicaltrials/hESC.aspx], Accessed 29th July 2011.

4. Geron Corporation: Press Release 23/01/09 - Geron receives FDA clearance to begin World's first human clinical trial of embryonic stem cell-based therapy. [http://www.geron.com/media/pressview.aspx?id=1148], Accessed 29th July 2011.

5. BBC News Online. [http://news.bbc.co.uk/1/hi/health/7847450.stm], Accessed 29th July 2011

6. Geron Corporation: Press Release 18/08/2009 - Geron's IND for spinal cord injury placed on hold. [http://www.geron.com/investors/factsheet/ pressview.aspx?id=1187], Accessed 29th July 2011.

7. Geron Corporation: Press Release $28 / 07 / 2010$ - Geron to proceed with first human clinical trial of embryonic stem cell-based therapy. [http:// www.geron.com/media/pressview.aspx?id=1229], Accessed 29th July 2011.

8. Marshall E: Gene therapy: Second child in French trial is found to have leukemia. Science 2003, 299:320-320.

9. Sekhon LHS, Fehlings MG: Epidemiology, demographics, and pathophysiology of acute spinal cord injury. Spine 2001, 26:S2-S12.

10. Bauchet L, Lonjon N, Perrin FE, Gilbert C, Privat A, Fattal C: Strategies for spinal cord repair after injury: a review of the literature and information. Ann Phys Rehabil Med 2009, 52:330-351.

11. National Spinal Cord Injury Statistic Centre: Facts and Figures at a Glance 2011. [https://www.nscisc.uab.edu/public_content/pdf/Facts $\% 202011 \%$ 20Feb\%20Final.pdf], Accessed 29th July 2011.

12. Potter PJ: Disordered control of the urinary bladder after human spinal cord injury: what are the problems? In Autonomic Dysfunction after Spinal Cord Injury. Volume 152. Amsterdam: Elsevier Science; 2006:51-57.

13. Ravenscroft A, Ahmed YS, Burnside IG: Chronic pain after SCl. A patient survey. Spinal Cord 2000, 38:611-614.

14. Kennedy P, Rogers BA: Anxiety and depression after spinal cord injury: A longitudinal analysis. Archives of Physical Medicine and Rehabilitation 2000, 81:932-937.

15. Kennedy P, Evans MJ: Evaluation of post traumatic distress in the first 6 months following SCI. Spinal Cord 2001, 39:381-386.

16. Noreau L, Fougeyrollas P: Long-term consequences of spinal cord injury on social participation: the occurrence of handicap situations. Disabil Rehabil 2000, 22:170-180.

17. McDonald JW, Sadowsky C: Spinal-cord injury. Lancet 2002, 359:417-425.

18. Tator $\mathrm{CH}$ : Update on the pathophysiology and pathology of acute spinal-cord injury. Brain Pathology 1995, 5:407-413.

19. Rowland JW, Hawryluk GWJ, Kwon B, Fehlings MG: Current status of acute spinal cord injury pathophysiology and emerging therapies: promise on the horizon. Neurosurgical Focus 2008, 25.

20. Kakulas BA: A review of the neuropathology of human spinal cord injury with emphasis on special features. J Spinal Cord Med 1999, 22:119-124.

21. Kakulas BA: Neuropathology: the foundation for new treatments in spinal cord injury. Spinal Cord 2004, 42:549-563.

22. Norenberg MD, Smith J, Marcillo A: The pathology of human spinal cord injury: Defining the problems. Journal of Neurotrauma 2004, 21:429-440.

23. Emery E, Aldana P, Bunge MB, Puckett W, Srinivasan A, Keane RW, Bethea J, Levi ADO: Apoptosis after traumatic human spinal cord injury. Journal of Neurosurgery 1998, 89:911-920.

24. Beattie MS, Farooqui AA, Bresnahan JC: Review of current evidence for apoptosis after spinal cord injury. J Neurotrauma 2000, 17:915-925.

25. Geron Corporation: GRNOPC1 Background Information. [http://www.geron. com/GRNOPC1Trial/grnopc1-backgrounder.pdf], Accessed 29th July 2011

26. Faulkner J, Keirstead HS: Human embryonic stem cell-derived oligodendrocyte progenitors for the treatment of spinal cord injury. Transplant Immunology 2005, 15:131-142.

27. Coutts M, Keirstead HS: Stem cells for the treatment of spinal cord injury. Experimental Neurology 2008, 209:368-377.

28. Thomson JA, Itskovitz-Eldor J, Shapiro SS, Waknitz MA, Swiergiel JJ, Marshall VS, Jones JM: Embryonic stem cell lines derived from human blastocysts. Science 1998, 282:1145-1147.

29. Rossi SL, Keirstead HS: Stem cells and spinal cord regeneration. Current Opinion in Biotechnology 2009, 20:552-562.

30. Kan EM, Ling EA, Lu J: Stem cell therapy for spinal cord injury. Curr Med Chem 2010, 17:4492-4510.

31. Mackay-Sim A, St John JA: Olfactory ensheathing cells from the nose: clinical application in human spinal cord injuries. Exp Neurol 2011, 229:174-180

32. Uccelli A, Benvenuto F, Laroni A, Giunti D: Neuroprotective features of mesenchymal stem cells. Best Pract Res Clin Haematol 2011, 24:59-64.

33. Rossi SL, Nistor G, Wyatt T, Yin HZ, Poole AJ, Weiss JH, Gardener MJ, Dijkstra S, Fischer DF, Keirstead HS: Histological and functional benefit 
following transplantation of motor neuron progenitors to the injured rat spinal cord. PLoS One 2010, 5(7):e11852.

34. Nistor GI, Totoiu MO, Haque N, Carpenter MK, Keirstead HS: Human embryonic stem cells differentiate into oligodendrocytes in high purity and myelinate after spinal cord transplantation. Glia 2005, 49(3):385-396.

35. Hatch MN, Nistor G, Keirstead HS: Derivation of High-Purity Oligodendroglial Progenitors. Neural Cell Transplantation 2009, 59-75.

36. Waxman SG: Demyelination in spinal-cord injury. Journal of the Neurological Sciences 1989, 91(12):1-14.

37. Totoiu MO, Keirstead HS: Spinal cord injury is accompanied by chronic progressive demyelination. Journal of Comparative Neurology 2005, 486(4):373-383.

38. Guest JD, Hiester ED, Bunge RP: Demyelination and Schwann cell responses adjacent to injury epicenter cavities following chronic human spinal cord injury. Exp Neurol 2005, 192(2):384-393.

39. Griffiths I, Klugmann M, Anderson T, Yool D, Thomson C, Schwab MH, Schneider A, Zimmermann F, McCulloch M, Nadon N, et al: Axonal swellings and degeneration in mice lacking the major proteolipid of myelin. Science 1998, 280(5369):1610-1613.

40. Lasiene J, Shupe L, Perlmutter S, Horner P: No evidence for chronic demyelination in spared axons after spinal cord injury in a mouse. Journal of Neuroscience 2008, 28(15):3887-3896

41. Siebert JR, Stelzner DJ, Osterhout DJ: Chondroitinase treatment following spinal contusion injury increases migration of oligodendrocyte progenitor cells. Exp Neurol 2011.

42. Su Z, Yuan Y, Chen J, Zhu Y, Qiu Y, Zhu F, Huang A, He C: Reactive Astrocytes Inhibit the Survival and Differentiation of Oligodendrocyte Precursor Cells by Secreted TNF-alpha. J Neurotrauma 2011, 28(6):1089-1100

43. Wang Y, Cheng X, He Q, Zheng Y, Kim DH, Whittemore SR, Cao QL: Astrocytes from the contused spinal cord inhibit oligodendrocyte differentiation of adult oligodendrocyte precursor cells by increasing the expression of bone morphogenetic proteins. J Neurosci 2011, 31(16):6053-6058.

44. Keirstead HS, Nistor G, Bernal G, Totoiu M, Cloutier F, Sharp K, Steward O: Human embryonic stem cell-derived oligodendrocyte progenitor cell transplants remyelinate and restore locomotion after spinal cord injury. Journal of Neuroscience 2005, 25(19):4694-4705.

45. Logan A, Berry M: Transforming growth factor-beta(1) and basic fibroblast growth-factor in the injured cns. Trends in Pharmacological Sciences 1993, 14(9):337-343.

46. Bareyre FM, Schwab ME: Inflammation, degeneration and regeneration in the injured spinal cord: insights from DNA microarrays. Trends in Neurosciences 2003, 26(10):555-563.

47. Menei P, Montero-Menei C, Whittemore SR, Bunge RP, Bunge MB: Schwann cells genetically modified to secrete human BDNF promote enhanced axonal regrowth across transected adult rat spinal cord. European Journal of Neuroscience 1998, 10(2):607-621.

48. Hagg T, Oudega M: Degenerative and spontaneous regenerative processes after spinal cord injury. J Neurotrauma 2006, 23(34):264-280.

49. McDonald JW, Belegu V: Demyelination and remyelination after spinal cord injury. J Neurotrauma 2006, 23(34):345-359.

50. Barnabe-Heider F, Goritz C, Sabelstrom H, Takebayashi H, Pfrieger FW, Meletis K, Frisen J: Origin of new glial cells in intact and injured adult spinal cord. Cell Stem Cell 2010, 7(4):470-482.

51. Zhang YW, Denham J, Thies RS: Oligodendrocyte progenitor cells derived from human embryonic stem cells express neurotrophic factors. Stem Cells Dev 2006, 15(6):943-952.

52. Sharp J, Frame J, Siegenthaler M, Nistor G, Keirstead HS: Human embryonic Stem Cell-Derived Oligodendrocyte Progenitor Cell Transplants Improve Recovery after Cervical Spinal Cord Injury. Stem Cells 2009.

53. Wilkins A, Majed H, Layfield R, Compston A, Chandran S: Oligodendrocytes promote neuronal survival and axonal length by distinct intracellular mechanisms: a novel role for oligodendrocyte-derived glial cell linederived neurotrophic factor. J Neurosci 2003, 23(12):4967-4974.

54. Schwab JM, Brechtel K, Mueller CA, Failli V, Kaps HP, Tuli SK, Schluesener HJ: Experimental strategies to promote spinal cord regeneration - an integrative perspective. Progress in Neurobiology 2006, 78(2):91-116.

55. Thoenen $H$, Sendtner M: Neurotrophins: from enthusiastic expectations through sobering experiences to rational therapeutic approaches. Nature Neuroscience 2002, 5:1046-1050.
56. McDonald JW, Steforska VG, Liu XZ, Shin H, Liu S, Choi DW: Neurotrophin potentiation of iron-induced spinal cord injury. Neuroscience 2002, 115(3):931-939.

57. Finnerup NB, Jensen TS: Spinal cord injury pain - mechanisms and treatment. European Journal of Neurology 2004, 11(2):73-82.

58. Weaver LC, Verghese P, Bruce JC, Fehlings MG, Krenz NR, Marsh DR: Autonomic dysreflexia and primary afferent sprouting after clipcompression injury of the rat spinal cord. I Neurotrauma 2001, 18(10):1107-1119.

59. Almad A, Sahinkaya FR, McTigue DM: Oligodendrocyte fate after spinal cord injury. Neurotherapeutics 2011, 8(2):262-273.

60. Geron Corporation: Press Release 11/11/09 - Geron collaborators publish data on hESC-derived glial progenitor cell therapy in cervical spinal cord injury. [http://www.geron.com/media/pressview.aspx?id=1196], Accessed 29th July 2011.

61. Kerr CL, Letzen BS, Hill CM, Agrawal G, Thakor NV, Sterneckert JL, Gearhart JD, All AH: Efficient differentiation of human embryonic stem cells into oligodendrocyte progenitors for application in a rat contusion model of spinal cord injury. Int J Neurosci 2010, 120(4):305-313.

62. Erceg S, Ronaghi M, Oria M, Rosello MG, Arago MA, Lopez MG, Radojevic I, Moreno-Manzano V, Rodriguez-Jimenez FJ, Bhattacharya SS, et al: Transplanted oligodendrocytes and motoneuron progenitors generated from human embryonic stem cells promote locomotor recovery after spinal cord transection. Stem Cells 2010, 28(9):1541-1549.

63. Cao Q, He Q, Wang Y, Cheng X, Howard RM, Zhang Y, DeVries WH, Shields CB, Magnuson DS, Xu XM, et al: Transplantation of ciliary neurotrophic factor-expressing adult oligodendrocyte precursor cells promotes remyelination and functional recovery after spinal cord injury. J Neurosci 2010, 30(8):2989-3001.

64. Precision Systems and Instrumentation LLC: Infinite Horizon Impactor. [http://www.presysin.com/Products/Infinite-Horizon-Impactor.aspx], Accessed 29th July 2011.

65. De La Torre JC: Spinal cord injury models. Progress in Neurobiology (Oxford) 1984, 22(4):289-344.

66. Burney RE, Maio RF, Maynard F, Karunas R: Incidence, characteristics, and outcome of spinal-cord injury at trauma centers in North-America. Archives of Surgery 1993, 128(5):596-599.

67. Tator CH, Koyanagi I: Vascular mechanisms in the pathophysiology of human spinal cord injury. Journal of Neurosurgery 1997, 86(3):483-492.

68. Young W: Spinal cord contusion models. Spinal Cord Trauma: Regeneration, Neural Repair and Functional Recovery 2002, 137:231-255.

69. Werner C, Mollenberg O, Kochs E, Schulte J: Sevoflurane improves neurological outcome after incomplete cerebral-ischemia in rats. British Journal of Anaesthesia 1995, 75(6):756-760.

70. Sheng HX, Wang HC, Homi HM, Spasojevic I, Batinic-Haberle I, Pearlstein RD, Warner DS: A no-laminectomy spinal cord compression injury model in mice. J Neurotrauma 2004, 21(5):595-603.

71. Barros TED, Molina A: Analysis of the sensitivity and reproducibility of the Basso, Beattie, Bresnahan (BBB) scale in Wistar rats. Clinics 2008, 63(1):103-108.

72. Akhtar AZ, Pippin JJ, Sandusky CB: Animal models in spinal cord injury: A review. Reviews in the Neurosciences 2008, 19(1):47-60.

73. Ben-David $\mathrm{U}$, Benvenisty N: The tumorigenicity of human embryonic and induced pluripotent stem cells. Nature Reviews Cancer 2011, 11(4):268-277.

74. Blum B, Benvenisty N: The tumorigenicity of human embryonic stem cells. Advances in Cancer Research 2008, 100:133-+.

75. Okarma T: Interview with Thomas Okarma, M.D., Ph.D.; CEO, Geron. Rejuvenation Res 2009, 12(4):295-300.

76. Okamura RM, Lebkowski J, Au M, Priest CA, Denham J, Majumdar AS: Immunological properties of human embryonic stem cell-derived oligodendrocyte progenitor cells. Journal of Neuroimmunology 2007, 192(12):134-144.

77. Drukker M, Katz G, Urbach A, Schuldiner M, Markel G, Itskovitz-Eldor J, Reubinoff B, Mandelboim O, Benvenisty N: Characterization of the expression of MHC proteins in human embryonic stem cells. Proceedings of the National Academy of Sciences of the United States of America 2002, 99(15):9864-9869.

78. Li L, Baroja ML, Majumdar A, Chadwick K, Rouleau A, Gallacher L, Ferber I, Lebkowski J, Martin T, Madrenas J, et al: Human embryonic stem cells possess immune-privileged properties. Stem Cells 2004, 22(4):448-456. 
79. Fairchild PJ, Robertson NJ, Minger SL, Waldmann H: Embryonic stem cells: protecting pluripotency from alloreactivity. Current Opinion in Immunology 2007, 19(5):596-602.

80. Hatch MN, Nistor GI, Keirstead HS: Oligodendrocyte Differentiation from Human Embryonic Stem Cells. In Human Stem Cell Manual: A Laboratory Guide.. 1 edition. Edited by: Loring J, Wesselschmidt RL, Schwartz PH. New York: Elsevier; 2007:210-226.

81. Sundberg M, Hyysalo A, Skottman H, Shin S, Vemuri M, Suuronen R, Narkilahti S: A xeno-free culturing protocol for pluripotent stem cellderived oligodendrocyte precursor cell production. Regen Med 2011, 6(4):449-460.

82. Cloutier F, Siegenthaler MM, Nistor G, Keirstead HS: Transplantation of human embryonic stem cell-derived oligodendrocyte progenitors into rat spinal cord injuries does not cause harm. Regen Med 2006, 1(4):469-479.

83. McLaren A: Ethical and social considerations of stem cell research. Nature 2001, 414(6859):129-131.

84. Zarzeczny A, Caulfield T: Emerging Ethical, Legal and Social Issues Associated with Stem Cell Research \& and the Current Role of the Moral Status of the Embryo. Stem Cell Reviews and Reports 2009, 5(2):96-101.

85. Lo B, Parham L: Ethical Issues in Stem Cell Research. Endocrine Reviews 2009, 30(3):204-213.

86. Bretzner F, Gilbert F, Baylis F, Brownstone RM: Target populations for firstin-human embryonic stem cell research in spinal cord injury. Cell Stem Cell 2011, 8(5):468-475.

87. Wirth E, Lebkowski JS, Lebacqz K: Response to Frederic Bretzner et al. "Target populations for first-in-human embryonic stem cell research in spinal cord injury". Cell Stem Cell 2011, 8(5):476-478.

88. Solbakk JH, Zoloth $L$ : The tragedy of translation: the case of "first use" in human embryonic stem cell research. Cell Stem Cell 2011, 8(5):479-481.

89. Geron Corporation: Press release 07/06/2011 - Geron Presents Data From GRNOPC1 Trial at International Conferences on Spinal Cord Medicine and Rehabilitation.[http://www.geron.com/media/pressview.aspx?id=1271], Accessed 29th July 2011

90. Wirth E, Priest C, Davies A, Cullen S, Denham J, Owens N, Sugianto A, Bacolini L, Reddy A, Okamura R, Lebkowski J: Update on a Phase 1 Safety Trial of Human Embryonic Stem Cell- Derived Oligodendrocyte Progenitor Cells (GRNOPC1) in Subjects with Neurologically Complete, Subacute Spinal Cord Injuries. Abstract from 2011 ISCoS Meeting [http:// www.iscos.org.uk/files/Oral Presentation Abstracts from the 2011 International Congress on Spinal Cord Medicine and Rehabilitation.pdf], Accessed 29th July 2011

91. Geron Corporation: Geron Corporation presentation at Jefferies 2011 global healthcare conference. [http://www.wsw.com/webcast/jeff60/gern/], Accessed 29th July 2011

92. Dobkin BH, Curt A, Guest J: Cellular transplants in China: Observational study from the largest human experiment in chronic spinal cord injury. Neurorehabilitation and Neural Repair 2006, 20(1):5-13.

93. Cohen $C B$, Cohen PJ: International stem cell tourism and the need for effective regulation. Part I: Stem cell tourism in Russia and India: clinical research, innovative treatment, or unproven hype? Kennedy Inst Ethics J 2010, 20(1):27-49.

94. Cohen $C B$, Cohen PJ: International stem cell tourism and the need for effective regulation. Part II: Developing sound oversight measures and effective patient support. Kennedy Inst Ethics J 2010, 20(3):207-230.

\section{Pre-publication history}

The pre-publication history for this paper can be accessed here: http://www.biomedcentral.com/1471-2377/11/113/prepub

doi:10.1186/1471-2377-11-113

Cite this article as: Watson and Yeung: What is the potential of oligodendrocyte progenitor cells to successfully treat human spinal cord injury? BMC Neurology 2011 11:113.

\section{Submit your next manuscript to BioMed Central and take full advantage of:}

- Convenient online submission

- Thorough peer review

- No space constraints or color figure charges

- Immediate publication on acceptance

- Inclusion in PubMed, CAS, Scopus and Google Scholar

- Research which is freely available for redistribution

Submit your manuscript at www.biomedcentral.com/submit
Biomed Central 